\title{
RELEMBRANDO SUZANA ALICE CARDOSO
}

\section{REMEMBERING SUZANA ALICE CARDOSO}

Jacyra Andrade Mota

Universidade Federal da Bahia, Salvador, Bahia, Brasil

jacymota@ufba.br

Resumo: Este texto traz para esta homenagem realizada pela ANPOLL, em seu XXIV Encontro Nacional, pequenos recortes da vida de Suzana Alice Cardoso, pesquisadora, professora, escritora, colega e amiga, que nos recordam a sua presença marcante nos vários caminhos que percorreu até 2 de maio de 2018, sempre com muita determinação, coragem, competência e sensibilidade. Os recortes se distribuem pela sua vida acadêmica, pela sua atividade como cidadã, pelas suas produções científicas e pelos relatos ficcionais, que se relacionam à sua vida pessoal.

Palavras-chave: Homenagem; Suzana Alice Cardoso; Geosociolinguística

\begin{abstract}
This text brings to this tribute held by ANPOLL, in its XXIV ${ }^{\text {th }}$ National Meeting, small excerpts from the life of Suzana Alice Cardoso, researcher, teacher, writer, colleague and friend, which remind us of her remarkable presence in the various paths she walked until May 2, 2018, always with great determination, courage, competence and sensitivity. The excerpts are distributed by her academic life, her activity as a citizen, her scientific productions, and the fictional reports that relate to her personal life.
\end{abstract}

Keywords: Tribute; Suzana Alice Cardoso; Geosociolinguistics 


\section{Formação acadêmica}

Graduada em Letras Neolatinas pela então Faculdade de Filosofia da Universidade Federal da Bahia, em 1960, iniciou-se como pós-graduanda em cursos de especialização ministrados em caráter intensivo, durante os Institutos de Linguística, o primeiro dos quais I Instituto Linguístico Latino-Americano - ocorreu na Universidad de la República, em Montevidéu, promovido pelo PILEI (Programa Interamericano de Linguística e Ensino de Idiomas), entre dezembro de 1965 e janeiro de 1966.

Implantado o curso de Mestrado na UFBA, participou da sua primeira turma, elaborando, sob a orientação de Nelson Rossi, a Dissertação Processos de negação em Gararu-Sergipe, defendida em 1980. A obtenção do grau de Doutor vai ocorrer em 2002, na UFRJ, com a tese Atlas linguístico de Sergipe II, publicada em 2005

\section{Professora e pesquisadora}

Logo após a graduação, Suzana Cardoso, por indicação de Nelson Rossi, passou a lecionar português no Portugiesisch Brasilianisches Institut da Universität zu Köln, Alemanha, onde foi leitora de 1961 a 1962, tendo trabalhado com o romanista Joseph Maria Piel, o que a credenciou, ao voltar, a ingressar como docente, na UFBA, como Regente da Cadeira de Língua Portuguesa, em substituição a Nelson Rossi, convidado a integrar o grupo de pesquisadores que constituiriam a Universidade de Brasília.

No período em que esteve na Alemanha, começou a frequentar os congressos internacionais da Société de Linguistique Romane, tendo participado, em Strasbourg, em abril de 1962, da sua X edição, organizada por Georges Straka e presidida por Walther von Wartburg e Charles Bruneau.

Tendo iniciado sua atividade profissional na Universidade Federal da Bahia, em 1963, continuou por 55 anos, interessada em participar da vida acadêmica até a véspera de seu falecimento, dia em que se comprometeu a produzir um capítulo sobre a sua gestão como presidente da Associação Brasileira de Linguística (ABRALIN), em atendimento à solicitação de Miguel Oliveira Jr., Presidente que programara incluir, entre os fatos comemorativos dos 50 anos da ABRALIN, em 2019, uma obra que trouxesse o testemunho de todas as gestões passadas.

Seguindo a trilha iniciada por Nelson Rossi, que não concebia a dissociação entre ensino e pesquisa, tendo sido um dos primeiros a introduzir atividades de pesquisa entre os estudantes graduandos, antes do surgimento dos atuais programas que subvencionam a Iniciação Científica, Suzana dedicou-se, continuamente, à docência e à pesquisa, inicialmente na graduação e, posteriormente, também na pós-graduação, contribuindo para a formação de inúmeros pesquisadores, muitos dos quais hoje também professores universitários.

Como pesquisadora, destaca-se a sua atuação na área de estudos geossociolinguísticos, iniciada, em 1965, com as pesquisas em Sergipe para a elaboração do Atlas linguístico de Sergipe - ALS (FERREIRA, C. et al, 1987), desenvolvidas juntamente com os demais professores da equipe baiana, continuada com a dissertação de Mestrado, em que trata dos processos de negação em Gararu, uma das localidades que fazem parte da rede de pontos do ALS, a Tese para Professor Assistente - O verbo e sua estrutura em Gararu (Sergipe), em 1973 - e a Tese de Doutorado, que dá continuidade ao primeiro volume do ALS.

Nessa mesma área, publicou as obras: A dialetologia no Brasil, em 1994, e O léxico rural, em 2000, ambas em coautoria com Carlota Ferreira; Geolinguística: tradição e modernidade, em 2010; e inúmeros artigos em periódicos especializados e capítulos de livros, quer sobre a própria área de estudos, quer sobre fatos linguísticos documentados no português do Brasil - algumas vezes comparando-os com dados de outras áreas de língua portuguesa. 
A dialetologia no Brasil integra a coleção "Repensando a língua portuguesa", coordenada por Ataliba T. de Castilho, que tinha como objetivo divulgar as diversas áreas de estudo, tornando-as acessíveis aos iniciantes, especialmente aos graduandos, como dizem as autoras na Apresentação:

O conteúdo deste livro tem objetivos e endereço muito nítidos. Procura reorganizar para aqueles que iniciam os estudos dialetais um conjunto de informações sobre o que fizeram estudiosos brasileiros, no campo da dialetologia: o que se escreveu sobre a língua do País, quem e quando. (FERREIRA, C.; CARDOSO, S., 1994, p. 9)

O léxico rural traz dados do Atlas prévio dos falares baianos - APFB (ROSSI, 1963) e do Atlas linguístico de Sergipe - ALS (FERREIRA et al., 1987), representando importante contribuição para a lexicografia brasileira.

Sobre o objetivo de Geolinguística: tradição e modernidade, observa a autora, em sua Apresentação:

A reflexão, pois, sobre os percursos seguidos pelos estudos dialetais, os caminhos e as trilhas percorridos pela sua metodologia constituem-se objeto principal deste livro, que tem um destino muito particular: os nossos alunos das disciplinas de dialetologia. (CARDOSO, 2010, p. 12)

Como exemplos da sua produção em artigos e capítulos de livros, citam-se: Dialetologia (CARDOSO, 2016); O atlas linguístico-etnográfico dos Açores e os atlas linguísticos da Bahia e de Sergipe: um encontro de dados (CARDOSO, 2010); Dequeísmo: um fenômeno da România Nova? (CARDOSO,1996); Empréstimos: uma questão linguística elou político-cultural? (CARDOSO, 1991), entre outros.

Suzana foi também organizadora, juntamente com alguns colegas, de Diversidade do português do Brasil. Estudos de dialectologia rural e outros, em 1988 -, que traz, principalmente, dados documentados na Bahia e em Sergipe; de Quinhentos anos de história linguística no Brasil, em 2006 - obra que reúne a contribuição de 23 pesquisadores, de diferentes linhas teóricas, e busca apresentar a variedade de línguas aqui presentes e o português do Brasil, após 500 anos; de seis dos sete volumes da série Documentos 1 — coleção que apresenta dados da pesquisa realizada para elaboração do Atlas linguístico do Brasil (ALiB) e análises preliminares dos dados.

O interesse pela área da Dialetologia e Sociolinguística vai culminar com a proposta de elaboração do Atlas linguístico do Brasil, no tocante à língua portuguesa, em 1996, apresentada ao Seminário Nacional Caminhos e Perspectivas para a Geolinguística no Brasil, seguida pela coordenação do Projeto, como Presidente do Comitê Nacional então instituído, tendo alcançado, em 2014, a publicação dos dois primeiros volumes - um introdutório e o outro com uma série de cartas linguísticas com informação diatópica (e, em alguns casos, também diassocial) dos dados documentados nas 25 capitais $^{2}$ que integram a rede de pontos do atlas (cf. CARDOSO et al., 2014).

$\mathrm{Na}$ abertura do Seminário Nacional Caminhos e Perspectivas para a Geolinguística no Brasil, ao propor a realização de um atlas linguístico do Brasil, referente à língua portuguesa, Suzana Cardoso apresenta a necessidade de implementar-se um projeto dessa natureza como "uma questão política", ressaltando que

\footnotetext{
${ }^{1}$ Cf. CARDOSO; MOTA (Orgs.), 2006; CARDOSO; MOTA; PAIM (Orgs.), 2012; CARDOSO, Suzana et al. (Orgs.), 2014, 2016, 2017.

${ }^{2}$ Brasília (DF) e Palmas (TO) não foram incluídas, em face da metodologia do Projeto ALiB, no tocante à data de fundação das cidades que constituem a sua rede de pontos.
} 
[...] É preciso ter-se a multidimensionalidade da língua no país não apenas para efeitos de precisar e demarcar espaços geolinguísticos, mas para que se possa também contribuir, de forma direta, para um melhor equacionamento entre a realidade de cada área e o ensino da língua materna que nela se processa. (CARDOSO, 1996, p. 91)

E, ao concluir a sua apresentação, assim conclama os pesquisadores presentes para a realização dessa tarefa:

Postas essas ideias, talvez movidas por muitos sonhos, porém fincadas com os pés no chão e não distanciadas da realidade do nosso país, espero que elas ecoem entre todos os interessados nos estudos dialetais, possam ser analisadas e criticadas, complementadas ou refeitas, mas que caminhem na direção da construção do atlas linguístico do Brasil. (CARDOSO, 1996, p. 96)

Suzana Cardoso integrou também o grupo responsável pelo Projeto de Estudo da Norma Urbana Culta no Brasil (Projeto NURC), em Salvador — projeto introduzido no Brasil por Nelson Rossi, em 1969, participando de todas as suas fases, desde a constituição do corpus à análise de dados.

Para dar continuidade à documentação em Salvador e propiciar a análise de dados em tempo real de curta duração, de acordo com a proposta laboviana (cf. LABOV, 1972), coordenou, na década de 1990, juntamente com Jacyra Mota, o Projeto de Estudo da Variação Linguística (PROVAR), constituindo um corpus com novos registros de informantes anteriormente gravados pelo Projeto NURC e de informantes soteropolitanos com o mesmo perfil - homens e mulheres, de nível universitário, estratificados em três faixas etárias mantendo a mesma metodologia dos registros anteriores.

Em sua atividade acadêmica, inclui-se também a participação como membro do Corpo Editorial de revistas ligadas a programas de pós-graduação, como Estudos Linguísticos e Literários (UFBA), desde 2005, da qual se tornou Editora Emérita ${ }^{3}$; $A$ cor das Letras (UEFS); ou de graduação, como Ingá: Revista de Estudos Linguísticos e Literários, publicação do Curso de Licenciatura em Letras da Universidade Federal do Recôncavo da Bahia. A partir de 2017, ao ingressar na Academia de Letras da Bahia, passa a integrar também o Conselho Editorial da Revista da Academia de Letras da Bahia.

\section{Atuação em órgãos colegiados}

Suzana Cardoso participou de vários órgãos colegiados, algumas vezes como dirigente. Candidatou-se a Diretora do Instituto de Letras, a Vice-Reitora e, por duas vezes (1987 e 1992), integrou a lista sêxtupla para a Reitoria da Universidade Federal da Bahia e, como observa em seu discurso de posse à Academia de Letras da Bahia, "não tendo sido a indicada para esses cargos, [a menina de Jacobina] soube, sempre, sentar-se ao lado do escolhido e com ele trabalhar diuturnamente" (CARDOSO, 2017, p. 275).

Em 2009, recebeu o reconhecimento da Universidade Federal da Bahia com a outorga do título de Professora Emérita.

\section{Atuação em associações}

A sua atividade constante em associações acadêmicas, de classe e religiosas, como ela própria declarou, em várias ocasiões, estava ligada à consciência cidadã e ao desejo de

\footnotetext{
${ }^{3}$ Cf. Portaria $n^{\circ} 14 / 2015$.
} 


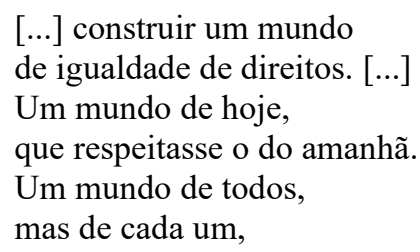

como se lê no poema publicado em Re-trato (CARDOSO, 2007, p. 136), obra que, segundo a autora,

É a fotografia de alguns episódios vividos e relatados. [...] É também 'pacto', 'intimidade', 'conversação' com e sobre o passado, porque trato é tudo isso e ainda mais, quando retomado no curso dos anos. (CARDOSO, 2007, p. 11)

\subsection{Associações científicas}

Suzana Cardoso foi sócia fundadora da Associação de Linguística e Filologia da América Latina (ALFAL), tendo passado, em 2017, à categoria de "sócia de honor" e da Associação Brasileira de Linguística (ABRALIN), que presidiu entre 1993 e 1995, tendo organizado, em 1994, o I Congresso Internacional dessa Associação.

No volume comemorativo dos 40 anos da ABRALIN, comenta, no capítulo "Caminhos da dialetologia brasileira":

É, pois, muito gratificante ter participado, em plena mocidade, da fundação de uma associação bem-sucedida, como a nossa ABRALIN, e, mais que isso, honroso ter assumido a sua presidência beirando a minha senectude, de 1993 a 1995. (CARDOSO, 2009, p. 138)

Coordenou o GT de Sociolinguística da Associação Nacional de Pós-Graduação em Letras e Linguística (ANPOLL), entre 1992 e 1994, promovendo o Seminário Nacional sobre a Diversidade Linguística e o Ensino da Língua Materna, em 1993, e organizando a publicação das comunicações apresentadas no evento em Diversidade linguística e ensino (CARDOSO, 1996).

Sobre esse GT e as duas grandes linhas que abarca - Sociolinguística e Dialetologia - comenta:

\footnotetext{
O nosso GT é um grupo de trabalho especial pela sua abrangência, e nem por isso deixa de ser um GT nos moldes estatutários da ANPOLL.

Embora se configurem na sua individualidade em dois ramos distintos e perfeitamente delimitáveis, Dialectologia e Sociolinguística, pelas imbricações e interfaces que entre elas se estabelecem, não devem constituir-se em GTs distintos, mas continuarem num 'casamento' duradouro e, até onde vislumbro, indissolúvel. (CARDOSO, 2009, p. 20)
}

Participou, como associada, do Grupo de Estudos do Nordeste (GELNE) e da Sociedade Brasileira para o Progresso da Ciência (SBPC). Foi membro da Société de Dialectologie et Geolinguistique (DiG), da Societé de Linguistique Romane e membro associado do LDI - Lexiques, Dictionnaires, Informatique, da Université de Paris 13, universidade em que foi também Professeur Invité. 


\subsection{Associações de classe}

Como um dos fundadores, em 1968, da Associação de Professores Universitários da Bahia (APUB) - hoje APUB-Sindicato - colaborou continuamente com a Associação, sempre em defesa da Democracia e do interesse dos professores.

\section{Academia de letras da Bahia}

Em 28 de abril de 2016, ingressou na Academia de Letras da Bahia, tendo publicado o seu discurso de posse na Revista da Academia de Letras da Bahia, n. 55 (2017).

No número 59 da mesma revista, a Presidente da Academia, Profa. Dra. Evelina Hoisel, assim se refere à sua passagem pela ABL: "Suzana Alice Marcelino Cardoso, desde o dia em que entrou na Academia de Letras da Bahia, [...] viveu de forma plena e generosa uma importante vertente de sua história, deixando a sua marca em tudo que nos legou (HOISEL, 2019, p. 300).

\section{Outras atividades}

Tendo participado da Juventude Universitária Católica (JUC), durante o período de graduação, continuou sempre engajada em atividades ligadas à religião e em trabalhos sociais desenvolvidos pela Igreja.

Com esse espírito participativo, integrou a Comissão de Justiça e Paz da Arquidiocese de Salvador, da qual foi coordenadora de 1988 a 1995, e participou, de 1988 a 2018, da Academia de Letras e Artes Mater Salvatoris - agremiação da Arquidiocese de Salvador, cuja principal finalidade, expressa no Art. $1^{\circ}$ do seu Estatuto, é louvar a Santíssima Virgem, Mãe de Deus, através das Letras e das Artes —, onde assumiu, de 2015 a 2017, o cargo de $2^{\text {a }}$ Secretária ${ }^{4}$.

Na revista dessa Academia publicou o seu discurso de posse, além de outros artigos, como "Maria Luigia Magnavita Galeffi” (cf. v. 2, p. 267-270, 1997) e "Língua e diversidade de usos" (cf. v. 6, p. 87-89, 2002).

A sua atenção e o seu engajamento em ações religiosas e sociais levaram-na, também, a publicar dois livros sobre as atividades do Padre Alfredo Haasler, em Jacobina: Padre Alfredo Haasler. Reflexões sobre um retrato (CARDOSO, 2007) e Alfredo de Deus, Alfredo dos pobres. Trajetória de um santo monge cisterciense em terras de Jacobina (CARDOSO, 2015).

\section{A Família e a terra natal}

Natural de Jacobina, município situado no extremo Norte da Chapada Diamantina, a 339 quilômetros de Salvador, Suzana foi sempre fiel à sua terra natal, onde, segundo o seu próprio relato em Re-trato (CARDOSO, 2007), desde muito jovem, foi despertada para a existência da variação linguística, ouvindo de uma das cozinheiras que trabalhavam em sua casa nomes como chamberlain e ampulhetas, respectivamente, para o guarda-chuva e para as ombreiras que se usavam nos vestidos.

Sobre Jacobina, publica "A marujada em Jacobina" (CARDOSO, 1984) e organiza, em coautoria, "Jacobina. Passado e futuro" (BRANDÃO; CARDOSO, 1993).

A família e a terra natal estão presentes ainda nas obras Re-trato (CARDOSO, 2007) e Casa-de-nós-todos. Um umbuzeiro sem umbuzada (CARDOSO, 2017).

\footnotetext{
${ }^{4} \mathrm{Cf}$. http://www.arquidiocesesalvador.org.br/mater-salvatoris-tem-nova-diretoria/. Acesso em: 14 set. 2019.
} 
$\mathrm{Na}$ primeira, dedicada à família, relata fatos de sua infância, agrupando-os em "Lições" e "Lembranças". Termina o livro com "Versos de algumas madrugadas" e "Páginas finais... que o tempo ditou", esta última parte dedicada aos netos.

Em Casa-de-nós-todos. Um umbuzeiro sem umbuzada, mescla realidade e ficção, dizendo, ao final, no que denomina "Um colofão especial":

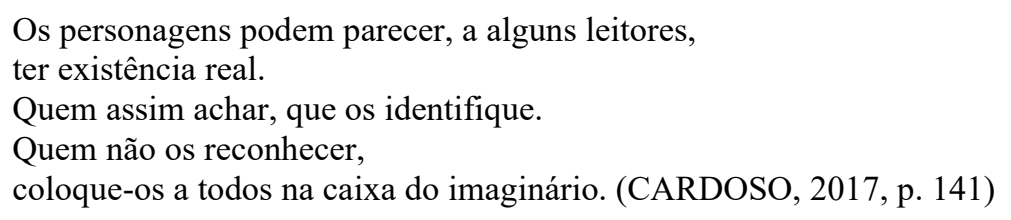

Ao terminar essa breve passagem pela vida de Suzana, trago o texto-despedida, que ela distribuiu aos colegas, amigos e familiares, presentes ao almoço comemorativo dos seus 80 anos, em 9 de novembro de 2017, intitulado " 8 pensamentos para 8 décadas de existir", em que diz:

\begin{abstract}
Aqui se põem singelas e encurtadas reflexões sobre temas essenciais na minha vida, oscilante entre extremos - amor e dor —, entre si complementares — esperança e fé —, roteiro do dia a dia — humildade e paciência — e, enfim, uma máxima de condução no meu caminhar — sabedoria e tolerância —, mas que só funcionam se conjuntamente vivenciados. Não devem ser vistas como 'lições' — jamais me arrogaria o direito de ministrá-las — , apenas devem ser lidas como um ‘sumário’ do passo a passo de 80 anos, 29.220 dias, 701.280 horas, 42.076.800 minutos, sedimentados em terras diversas, vividos em partilha com muitos, ancorados na amizade dos que se ligam ao meu coração [...]
\end{abstract}

\title{
Referências
}

Brandão, Maria Azevedo; Cardoso, Suzana Alice (Orgs.). Jacobina. Passado e futuro. Jacobina: ACIJA, 1993, p. 29-38.

Cardoso, Suzana Alice. O verbo e sua estrutura em Gararu-Sergipe. Tese (Concurso para Professor Assistente) - Universidade Federal da Bahia, Salvador, BA, 1973.

Cardoso, Suzana Alice. Processos de negação no dialeto de Gararu (Sergipe).1980. 118f. Dissertação (Mestrado em Letras e Linguística) - Universidade Federal da Bahia, Salvador, BA, 1980.

Cardoso, Suzana Alice. A marujada em Jacobina. Revista Lusitana - Nova Série, v. 5, Lisboa, p. 35-43, 1984. Disponível em: https://jacobinanews.wordpress.com/2015/11/11/marujada-dejacobina-alerta-quem-dorme-ha-mais-de-duzentos-anos; e em http://marujadadesaubara.org.br/encontros/i-encontro-de-chegancas-da-bahia/quemparticipa/cheganca-marujada-de-jacobina/ Acesso em: 13 jun. 2019.

Cardoso, Suzana Alice. Empréstimos: uma questão linguística e/ou político-cultural? Revista Internacional de Lingua Portuguesa, v. 5/6, Lisboa, 1991, p. 9-17.

Cardoso, Suzana Alice. Discurso de posse na Academia de Letras e Artes. Mater Salvatoris. Salvador, Academia de Letras Mater Salvatoris, 1992. 
Cardoso, Suzana Alice. Dequeísmo: um fenômeno da România Nova? Estudos Linguísticos e Literários, n. especial, Salvador, 1996, p. 239-246.

Cardoso, Suzana Alice. O Atlas lingüístico do Brasil: uma questão política. Seminário Nacional Caminhos e Perspectivas para a Geolinguística no Brasil. 1, 1996, Salvador. Atas... Salvador: Serviço de Reprografia da Pró-Reitoria de Planejamento da UFBA, 1996, p. 87- 96.

Cardoso, Suzana Alice (Org.). Diversidade linguística e ensino. Salvador: EDUFBA, 1996.

Cardoso, Suzana Alice. Atlas linguístico de Sergipe II (Universidade Federal do Rio de Janeiro. Doutorado em Letras Vernáculas, 2002.

Cardoso, Suzana Alice. Atlas linguístico de Sergipe II. Salvador: EDUFBA, 2005.

Cardoso, Suzana Alice. Padre Alfredo Haasler. Reflexões sobre um retrato. Salvador: Vento Leste, 2007.

Cardoso, Suzana Alice. Re-trato. Salvador: Quarteto, 2007.

Cardoso, Suzana Alice. "Caminhos da dialetologia brasileira". In: Hora, Dermeval; Alves, Eliane; Espíndola, Lucienne (Orgs.). ABRALIN: 40 anos em cena. João Pessoa: Editora Universitária, 2009, p. 135-171.

Cardoso, Suzana Alice. GT de Sociolinguística da ANPOLL: passado, presente e futuro. In: Barretto, Mônica; Salgado; Ana Cláudia. Sociolinguística no Brasil: uma contribuição dos estudos sobre línguas em/de contato em homenagem ao professor Jürgen Heye. Rio de Janeiro: 7Letras, 2009, versão em CD.

Cardoso, Suzana Alice. Geolinguística: tradição e modernidade. São Paulo: Parábola, 2010.

Cardoso, Suzana Alice. "O atlas linguístico-etnográfico dos Açores e os atlas linguísticos da Bahia e de Sergipe: um encontro de dados". In: Ramos, Conceição de Maria de Araújo et al. (Orgs.). Pelos caminhos da dialetologia e da sociolinguística: entrelaçando saberes e vidas. Homenagem a Maria do Socorro Aragão. São Luís: EDUFMA, 2010, p. 111-123.

Cardoso, Suzana Alice. Alfredo de Deus, Alfredo dos pobres. Trajetória de um santo monge cisterciense em terras de Jacobina. Salvador: Quarteto, 2015.

Cardoso, Suzana Alice. "Dialetologia". In: Mollica; M. C.; Ferrarezi JR., C. (Orgs.). Sociolinguística, sociolinguísticas: uma introdução. São Paulo: Contexto, 2016, p. 13-22.

Cardoso, Suzana Alice. Discurso de posse. Revista da Academia de Letras da Bahia, n. 55, mar. 2017, p. 255-277. Disponível em: https://academiadeletrasdabahia.files.wordpress.com/2017/03/revista-da-alb-55-para-o-site20-02-2017.pdf. Acesso em: 14 jun. 2019.

Cardoso, Suzana Alice. 8 pensamentos para 8 décadas de existir. 2018. [No Prelo].

Cardoso, Suzana; MOTA, Jacyra (Orgs.). Documentos 2. Projeto Atlas Lingüístico do Brasil. 
Salvador: Quarteto, 2006.

Cardoso, Suzana Alice; Mota, Jacyra; Mattos e Silva, Rosa Virgínia (Orgs.). Quinhentos anos de história lingüística do Brasil. Salvador: Secretaria da Cultura e Turismo do Estado da Bahia, 2006.

Cardoso, Suzana; Mota, Jacyra; Paim, Marcela (Orgs.). Documentos 3. Vozes do X WORKALiB. Amostras do português brasileiro. Salvador: Vento Leste, 2012.

Cardoso, Suzana Alice et al. Atlas linguístico do Brasil. Londrina: EDUEL, v. I, v. II, 2014.

Cardoso, Suzana et al. (Orgs.). Documentos 4. Projeto Atlas Linguístico do Brasil: etapas concluídas, caminhos a trilhar. Salvador: Quarteto, 2014.

Cardoso, Suzana et al. (Orgs.). Documentos 6. Projeto Atlas Linguístico do Brasil: histórias e memórias. Salvador: Quarteto, 2016.

Cardoso, Suzana et al. (Orgs.). Documentos 7. Projeto Atlas Linguístico do Brasil: 20 anos de história. Salvador: Quarteto, 2017.

Ferreira, Carlota et al. Atlas linguístico de Sergipe. Salvador: UFBA-FUNDESC, 1987.

Ferreira, Carlota et al. (Orgs.). Diversidade do português do Brasil. Estudos de dialectologia rural e outros. Salvador: Centro Editorial e Didático da UFBA, 1988.

Ferreira, C.; CARDOSO, S. A dialetologia no Brasil. São Paulo: Contexto,1994.

Hoisel, Evelina. Sessão da Saudade: à memória de Suzana Alice Marcelino Cardoso, Revista da Academia de Letras da Bahia, n. 57, mar. 2017, p. 289-321. Disponível em: https://academiadeletrasdabahia.files.wordpress.com/2019/03/revista-da-alb-57.pdf. Acesso em: 14 set. 2019.

Labov, William. Sociolinguistic patterns. Philadelphia: University of Pennsylvania Press, 1972.

Rossi, Nelson. Atlas prévio dos falares baianos. Rio de Janeiro: Instituto Nacional do Livro, Ministério da Educação e Cultura, 1963.

Recebido em: 20 de julho de 2019 Aceito em: 28 de setembro de 2019 Publicado em: Dezembro de 2019 